Grant-in-Aid for Scientific Research (S)

Real Estate Markets, Financial Crisis, and Economic Growth : An Integrated Economic Approach

Working Paper Series No.2

\author{
Aging and Real Estate Prices: \\ Evidence from Japanese and US Regional Data
}

\author{
Yumi Saita \\ Chihiro Shimizu \\ Tsutomu Watanabe
}

December, 2013

HIT-REFINED PROJECT

Institute of Economic Research, Hitotsubashi University

Naka 2-1, Kunitachi-city, Tokyo 186-8603, JAPAN

Tel: +81-42-580-9145

E-mail: hit-tdb-sec@ier.hit-u.ac.jp

http://www.ier.hit-u.ac.jp/ifn/ 


\title{
Aging and Real Estate Prices: Evidence from Japanese and US Regional Data
}

\author{
Yumi Saita* \\ Chihiro Shimizu ${ }^{\dagger}$ \\ Tsutomu Watanabe ${ }^{\ddagger}$
}

First draft: August 25, 2013

This version: December 3, 2013

\begin{abstract}
In this paper, we empirically investigate how real estate prices are affected by aging. We run regional panel regressions for Japan and the United States. Our regression results show that, both in Japan and the U.S., real estate prices in a region are inversely correlated with the old age dependency ratio, i.e. the ratio of population aged $65+$ to population aged 20-64, in that region, and positively correlated with the total number of population in that region. The demographic factor had a greater impact on real estate prices in Japan than in the U.S. Based on the regression result for Japan and the population forecast made by a government agency, we estimate the demographic impact on Japanese real estate prices over the next 30 years. We find that it will be -2.4 percent per year in 2012-2040 while it was -3.7 percent per year in 1976-2010, suggesting that aging will continue to have downward pressure on land prices over the next 30 years, although the demographic impact will be slightly smaller than it was in 1976-2010 as the old age dependency ratio will not increase as much as it did before.
\end{abstract}

JEL Classification Number: G12; J11

Keywords: aging; dependency ratio; declining population; real estate prices

\footnotetext{
${ }^{*}$ Hitotsubashi University. We would like to thank Kyung-Hwan Kim, Yongheng Deng, Chang-Moo Lee, Kiyohiko Nishimura, Yasuhiro Nakagami, Tomoo Inoue, Hiroyuki Kasahara, and participants at the 27th IUSSP International Population Conference for useful discussions, and Yasuhito Kawamura for helping us to collect data. This research forms part of a project on "Understanding Deflation in Japan" funded by a JSPS Grant-in-Aid for Scientific Research (No. 24223003).

${ }^{\dagger}$ Reitaku University and University of British Columbia

${ }^{\ddagger}$ Graduate School of Economics, University of Tokyo. watanabe@e.u-tokyo.ac.jp.
} 


\section{Introduction}

Aging in Japan are advancing faster than in other major developed nations, and this is expected to have substantial effects on the country's economic systems, including its social security system. ${ }^{1}$ What kind of effect will the falling birthrate, aging society, and declining population have on the real estate market? Will the often mentioned real estate price asset meltdown really occur? The purpose of this paper is to address these questions by investigating how much demographic factors affected real estate prices in Japan and the U.S. To do so, we construct regional panel data covering over a quarter-century in Japan and the U.S., and then conduct regional panel data regressions to estimate the impact of demographic changes on real estate prices.

Looking back at fluctuations in Japan's real estate prices, if one excludes the temporary period of economic turmoil following the oil crisis in the mid-1970s, real estate prices continued to rise consistently from the end of World War II until the collapse of the bubble in the first half of the 1990s. In particular, the speed of growth increased at the start of the 1980s, gathered momentum in the latter half of the decade, reached a peak in 1991, and then abruptly entered a downward phase. At the start of the 2000s, real estate prices showed signs of bottoming out, then, in the middle of the decade, they entered a period of recovery which became known as the "mini-bubble". However, it entered a downward phase once again following the global financial crisis in 2008 .

In terms of the factors underlying these fluctuations in real estate prices, it is to be expected that economic growth, monetary policy, banks' lending behaviors and so forth had a major effect, but the effect of population cannot be overlooked either. In our previous study (Shimizu and Watanabe 2010), we show that home ownership rates in Japan tend to rise significantly from age 35 through 45 , and that the population in this age group creates new housing demand. In fact, the 1980s housing bubble overlapped with the period when the first wave of baby boomers entered this age group, creating the greatest housing demand since the war. When housing prices turned upward in the 2000s, significant housing demand was created by the second wave of baby boomers - the children of the first wave.

Research on the relationship between demographic changes and real estate prices has been started by Mankiw and Weil (1989), which argue that US housing demand would peak in the 1980s due to the baby boomer generation, making a prediction that housing prices

\footnotetext{
${ }^{1}$ See, for example, The Economist's report on Japan (The Economist, Special Report on Japan, November 20, 2010) which states that "Japan is aging faster than any country in history, with vast consequences for its economy."
} 
will subsequently decline 47 percent in real terms by $2007 .^{2}$ For Japan, Ootake and Shintani (1996) estimate housing demand employing a housing demand index similar to that proposed by Mankiw and Weil (1989), showing that demographic changes have an effect on housing price fluctuations in the short term, where housing supply is not elastic to price changes, but that in the long term, demographic factors do not affect housing prices as housing supply increases in response to an increase in demand. A similar result is reported by Shimizu and Watanabe (2010) and Nagahata et al. (2004). In contrast, Nakamura and Saita (2007) shows that demographic changes are related to housing price fluctuations even in the long run.

The debate on the impact of demographic changes on real estate prices has been recently restarted by Nishimura (2011) who argue that the Japanese real estate bubble in the late 1980s and its collapse in the early 1990s are closely related with demographic changes in Japan. Nishimura and Takáts (2012) presents a theoretical model to show that demographic changes are related to real estate prices and money demand. Takáts (2012) empirically test the relationship between demographic changes and housing prices using panel data for 21 countries, showing the presence of statistically significant correlation between the two. In this paper, we take Nishimura (2011) and Takáts (2012) as a starting point, but we focus on the relationship between demographic changes and real estate price fluctuations across regions in a country. We employ regional panel data for Japan and the U.S., covering a period that includes the Japanese 1980s land price bubble and the U.S. 2000s housing bubble, and examine the relationship between the two.

The rest of the paper is organized as follows. Section 2 explains our empirical method and the data employed. Section 3 provides estimation results. In Section 4, based on the regression result for Japan and the population forecast released by National Institute of Population and Social Security Research (IPSS), we estimate the demographic impact on Japanese real estate prices over the next 30 years. Section 5 concludes the paper.

\footnotetext{
${ }^{2}$ In 1991, a special issue of Regional Science and Urban Economics featuring critical essays on Mankiw and Weil (1989) was published. The following problems were pointed out: a) the fact that changes in housing demand have an effect on rental prices, not on selling prices; b) the fact that housing supply is elastic in the long term, so even if there is a change in housing demand, housing prices will not be affected due to the adjustment of housing supply; and c) the fact that since housing prices should respond immediately when an increase in housing demand is anticipated, the housing demand for a given year alone will not affect housing prices. The special issue also included analysis based on the same technique conducted by Engelhardt and Poterba (1991) that focused on Canada, with the reported results showing that no statistically significant relationship was observed with the estimated housing demand index and housing price fluctuations.
} 


\section{Empirical Method and Data}

\subsection{Empirical method}

Housing is one of the largest assets for individuals, which is acquired throughout one's younger working years and consumed in one's older years. This is why age group-based demographics have an effect on new housing demand. Figure 1 shows household home ownership rates by age (i.e. the age of the household head). One can see that, in Japan, home ownership rates rise rapidly from age 35 through 44 . In the U.S., on the other hand, home-ownership demand is already appearing at age 25. As a result, the period when the incidence of housing demand is most noticeable starts earlier than in Japan, from age 30 to 44. From 1980 onward, this trend has not changed much in either Japan or the U.S., and by the age of 60 , home ownership rates reach 80 percent in both countries.

Takáts (2012) and Nishimura and Takáts (2012) construct a simple overlapping generation model, following Samuelson (1958) and Diamond (1965), in which young agents are assumed to purchase housing assets but old agents do not, so that housing demand depends on the number of total population as well as on the young-to-old ratio, yielding a relationship between demographic changes and housing prices. The regression equation implied by this model is as follows. ${ }^{3}$

$$
\Delta \ln P_{i t}=\alpha+\beta \Delta \ln \mathrm{GDPPC}_{i t}+\gamma \Delta \ln \mathrm{OLDDEP}_{i t}+\delta \Delta \ln \mathrm{TPOP}_{i t}+\epsilon_{i t}
$$

where $P_{i t}$ represents real housing price for region $i$ in year $t$, GDPPC is per capita GDP, OLDDEP is the old age dependency ratio, which is defined by the ratio of population aged $65+$ to the working population (i.e. population aged 20-64), and TPOP is total population. The disturbance term is represented by $\epsilon_{i t}$. We will use Eq. (1) as our baseline regression equation in our empirical exercises after adding some modifications, which will be explained later.

\section{$2.2 \quad$ Data}

We construct regional price data for Japan and the U.S. With regard to the U.S., we use the state-by-state housing price index published by the Office of Federal Housing Finance Agency (FHFA). This index, which has been published since 1975, is estimated with the traditional repeat sales method. We convert this index into dollar values by using the median of dollar transaction prices in 1975, which is published also by FHFA for each state.

\footnotetext{
${ }^{3}$ See Takáts (2012) for more details on the derivation of this equation.
} 
For Japan, however, no region-by-region quality-adjusted housing price indexes covering the entire country exist. The only real estate price data available by region is the land price data published each year as of January 1st by the Ministry of Land, Infrastructure, Transport and Tourism, which have been used in many previous studies on the relationship between demographic changes and land prices, including Nagahata et al. (2004). However, as argued by Shimizu and Nishimura (2006) among others, this land price data is not reliable, since they are not transaction prices but appraisal prices, and some distortions are added by appraisers.

To minimize the distortion in land prices, we conduct quality adjustment using hedonic regression of the form

$$
\ln p_{j t}=\sum_{k=0}^{K} \beta_{k} X_{j k t}+\sum_{s=0}^{\tau} \delta_{s} D_{s}+\nu_{j t},
$$

where $p_{j t}$ represents the nominal land price for a property $j$ in year $t, X_{j k t}$ is the attributes associated with property $j, D_{s}$ is a time dummy, and $\epsilon_{i t}$ is a disturbance term. Note that $D_{s}$ is equal to 1 for $s=1$ (i.e. $D_{1}$ represents the constant term), and that, for $s>1, D_{s}$ is equal to 1 if $s=t$ and zero otherwise. For the land attributes, we use area $\left(m^{2}\right)$, building to land ratio, floor area ratio, distance to the nearest station, and time to the largest commercial center in the prefecture. ${ }^{4}$ The regression results are summarized in Table 1.

\footnotetext{
${ }^{4}$ The prefectural center is defined as follows. For each prefecture, we generate a buffer from the highest price location and define the mesh center point with the highest office density as the prefectural center.
} 
Table 1: Hedonic Regressions of Real Land Prices

\begin{tabular}{|c|c|c|c|c|c|c|c|c|}
\hline Prefecture & $\begin{array}{r}\text { Constant } \\
\text { term }\end{array}$ & Acreage & $\begin{array}{l}\text { Building to } \\
\text { land ratio }\end{array}$ & $\begin{array}{r}\text { Floor area } \\
\text { ratio }\end{array}$ & $\begin{array}{r}\text { Distance to } \\
\text { nearest station }\end{array}$ & $\begin{array}{l}\text { Distance to } \\
\text { urban center }\end{array}$ & $\begin{array}{r}\text { Adjusted } \\
\text { R-squared }\end{array}$ & N. Obs \\
\hline Hokkaido & 9.882 & -0.890 & 1.370 & -0.070 & -0.025 & 0.000 & 0.246 & 27,225 \\
\hline Aomori & 10.021 & -0.902 & 6.759 & 0.351 & -0.024 & -0.003 & 0.335 & 5,456 \\
\hline Iwate & 10.069 & -1.012 & 1.783 & 0.958 & 0.006 & -0.010 & 0.505 & 3,528 \\
\hline Miyagi & 10.588 & -0.913 & 0.028 & -0.359 & -0.050 & 0.000 & 0.357 & 11,559 \\
\hline Akita & 10.163 & -1.022 & -1.666 & 0.479 & -0.060 & -0.015 & 0.504 & 3,698 \\
\hline Yamagata & 10.199 & -1.124 & 4.141 & 0.112 & -0.066 & -0.010 & 0.512 & 3,507 \\
\hline Fukushima & 10.453 & -1.021 & -2.237 & 0.275 & -0.042 & -0.008 & 0.463 & 9,364 \\
\hline Ibaraki & 10.237 & -0.829 & 0.647 & 0.587 & -0.036 & 0.000 & 0.532 & 16,250 \\
\hline Tochigi & 10.689 & -1.177 & -0.522 & 0.217 & -0.052 & -0.012 & 0.618 & 9,612 \\
\hline Gunma & 10.442 & -0.675 & -0.450 & 0.056 & -0.056 & -0.013 & 0.639 & 7,941 \\
\hline Saitama & 11.362 & -0.582 & 0.057 & 0.589 & -0.075 & -0.029 & 0.754 & 31,476 \\
\hline Chiba & 11.334 & -0.870 & 1.676 & 0.049 & -0.148 & -0.015 & 0.573 & 30,689 \\
\hline Tokyo & 11.192 & 0.742 & 3.870 & 1.920 & -0.217 & 0.000 & 0.663 & 55,352 \\
\hline Kanagawa & 11.130 & 0.088 & -0.001 & -0.710 & -0.089 & 0.000 & 0.752 & 45,665 \\
\hline Niigata & 10.733 & -1.402 & 1.224 & -0.206 & -0.054 & -0.007 & 0.462 & 8,230 \\
\hline Toyama & 10.153 & -0.567 & 0.863 & 0.406 & -0.063 & -0.018 & 0.533 & 4,355 \\
\hline Ishikawa & 10.542 & -1.178 & 0.655 & 0.162 & -0.008 & -0.011 & 0.514 & 4,320 \\
\hline Fukui & 10.620 & -0.493 & -0.261 & -1.033 & -0.079 & -0.010 & 0.551 & 2,338 \\
\hline Yamanashi & 10.130 & -0.919 & 1.588 & 0.515 & -0.058 & -0.006 & 0.723 & 3,118 \\
\hline Nagano & 10.277 & -0.924 & -0.412 & 0.408 & -0.028 & -0.007 & 0.498 & 5,743 \\
\hline Gifu & 10.445 & -0.926 & 0.781 & 0.491 & -0.030 & -0.009 & 0.555 & 6,946 \\
\hline Shizuoka & 10.374 & -0.939 & 2.146 & 0.660 & -0.036 & 0.000 & 0.643 & 14,365 \\
\hline Aichi & 10.481 & -0.084 & 1.416 & -0.528 & -0.070 & 0.000 & 0.597 & 37,281 \\
\hline Mie & 10.075 & -0.897 & 2.335 & -0.157 & -0.062 & -0.004 & 0.619 & 9,116 \\
\hline Shiga & 11.126 & -1.507 & 1.516 & -0.062 & -0.074 & -0.022 & 0.737 & 6,021 \\
\hline Kyoto & 11.236 & -0.061 & 3.512 & 0.176 & -0.068 & -0.027 & 0.814 & 13,996 \\
\hline Osaka & 10.787 & 0.078 & 1.135 & 1.610 & -0.115 & 0.000 & 0.625 & 38,451 \\
\hline Hyogo & 11.046 & -0.231 & 4.023 & 0.216 & -0.175 & 0.000 & 0.421 & 28,558 \\
\hline Nara & 11.108 & -0.315 & 3.180 & -0.970 & -0.103 & -0.032 & 0.790 & 9,297 \\
\hline Wakayama & 10.749 & -0.733 & -0.126 & 0.115 & 0.016 & -0.009 & 0.568 & 3,396 \\
\hline Tottori & 10.783 & -1.621 & -0.214 & -1.653 & -0.086 & -0.003 & 0.398 & 2,198 \\
\hline Shimane & 10.011 & -0.831 & 0.360 & -0.200 & -0.031 & -0.005 & 0.359 & 2,491 \\
\hline Okayama & 10.317 & -1.843 & 1.654 & 0.703 & -0.046 & 0.000 & 0.558 & 8,116 \\
\hline Hiroshima & 10.859 & -1.593 & 0.019 & 0.716 & -0.051 & 0.000 & 0.343 & 13,452 \\
\hline Yamaguchi & 10.011 & -0.927 & -0.160 & 0.432 & -0.060 & 0.002 & 0.487 & 6,271 \\
\hline Tokushima & 10.227 & -0.011 & -2.632 & 0.692 & -0.030 & -0.019 & 0.641 & 2,762 \\
\hline Kagawa & 11.283 & -1.311 & 0.138 & 0.633 & -0.142 & -0.021 & 0.640 & 3,216 \\
\hline Ehime & 10.466 & -1.162 & 1.147 & 0.696 & -0.014 & -0.009 & 0.576 & 4,881 \\
\hline Kochi & 10.835 & -1.453 & -1.898 & 0.355 & -0.002 & -0.011 & 0.468 & 2,910 \\
\hline Fukuoka & 9.830 & 0.005 & 1.683 & 0.301 & -0.076 & 0.000 & 0.367 & 19,827 \\
\hline Saga & 9.936 & -1.334 & 1.825 & 0.102 & -0.030 & -0.015 & 0.469 & 2,256 \\
\hline Nagasaki & 10.268 & -0.573 & -0.553 & 0.092 & -0.040 & -0.012 & 0.379 & 5,427 \\
\hline Kumamoto & 9.888 & -1.011 & 0.187 & 0.478 & -0.030 & -0.014 & 0.657 & 5,684 \\
\hline Oita & 10.114 & -0.493 & -0.121 & 0.863 & -0.044 & -0.015 & 0.517 & 4,939 \\
\hline Miyazaki & 10.293 & -1.543 & 2.278 & -0.311 & -0.035 & -0.010 & 0.583 & 4,833 \\
\hline Kagoshima & 11.020 & -2.285 & -1.084 & -0.848 & -0.030 & -0.002 & 0.368 & 5,398 \\
\hline Okinawa & 10.728 & -2.706 & -2.026 & 1.020 & 0.156 & -0.003 & 0.594 & 3,703 \\
\hline
\end{tabular}

Note: Dependent variable is the log of real land price in each prefecture. The indicated acreage, building-to-land ratio, floor area ratio, distance to nearest station, and distance to major urban center coefficient estimates are multiplied by 1,000 . 
Table 2: Sources of Employed Data

\begin{tabular}{|c|c|c|}
\hline & Prefectural panel data for Japan & State panel data for U.S. \\
\hline Sample period & 1976 to 2010 & 1975 to 2011 \\
\hline Real estate prices & $\begin{array}{l}\text { Ministry of Land, Infrastructure, } \\
\text { Transport and Tourism, "Official land } \\
\text { prices". We use land prices only for } \\
\text { residential use, which are quality } \\
\text { adjusted by hedonic regression. }\end{array}$ & $\begin{array}{l}\text { Housing price data from Federal Hous- } \\
\text { ing Finance Agency ("All-transactions } \\
\text { Indexes" and "Summary statistics for } \\
\text { house prices") }\end{array}$ \\
\hline Per capita GDP & $\begin{array}{l}\text { Cabinet Office, "Prefectural economic } \\
\text { accounts" }\end{array}$ & $\begin{array}{l}\text { Bureau of Economic Analysis, "GDP } \\
\text { by state" }\end{array}$ \\
\hline Interest rate & $\begin{array}{l}\text { Bank of Japan, "Average contractual } \\
\text { interest rate on bank loans" }\end{array}$ & $\begin{array}{l}\text { Federal Reserve Board, "Contract rate } \\
\text { on 30-year, fixed-rate conventional } \\
\text { home mortgage commitments" }\end{array}$ \\
\hline Consumer price & $\begin{array}{l}\text { Statistics Bureau of Japan, "Consumer } \\
\text { price index" by prefecture }\end{array}$ & $\begin{array}{l}\text { Bureau of Labor Statistics, "CPI for all } \\
\text { items" by state }\end{array}$ \\
\hline New housing supply & $\begin{array}{l}\text { Ministry of Land, Infrastructure, } \\
\text { Transport and Tourism, new hous- } \\
\text { ing starts in "Statistical survey of } \\
\text { construction starts" }\end{array}$ & $\begin{array}{l}\text { U.S. Census, New privately-owned } \\
\text { housing units authorized by building } \\
\text { permits in "Building permits survey" }\end{array}$ \\
\hline Population by age group & $\begin{array}{l}\text { Ministry of Internal Affairs and Com- } \\
\text { munications, "National Census". For } \\
\text { years in which the census is not avail- } \\
\text { able, we use estimates by National In- } \\
\text { stitute of Population and Social Secu- } \\
\text { rity Research. }\end{array}$ & $\begin{array}{l}\text { U.S. Census, population by age and } \\
\text { state in "State population estimates" }\end{array}$ \\
\hline
\end{tabular}

Quality adjusted land prices are given by

$$
\ln \hat{p}_{j t}=\sum_{k=1}^{K} \hat{\beta}_{k} X_{j k}+\hat{\delta}_{1}+\hat{\delta}_{t} ; \quad \ln \hat{p}_{j 1}=\sum_{k=1}^{K} \hat{\beta}_{k} X_{k}+\hat{\delta}_{1}
$$

where $\hat{\beta}_{k}, \hat{\delta}_{1}$, and $\hat{\delta}_{t}$ are estimated parameters. Eq (3) implies

$$
\ln \left(\hat{p}_{j t} / \hat{p}_{1}\right)=\widehat{\delta}_{t}
$$

and

$$
\ln \left(\hat{p}_{j t} / \hat{p}_{j t-1}\right)=\hat{\delta}_{t}-\hat{\delta}_{t-1}
$$

Table 2 provides the sources of the six variables employed in our empirical exercise (i.e. real estate prices, population, the old age dependency ratio, the interest rate, and new housing supply). Regional unit is prefecture in Japan and state in the U.S. The sample period is 1976 to 2010 for Japan, and 1975 to 2011 for the U.S. 


\subsection{Demographic changes}

Figure 2 shows the evolution of populations by age group. We focus on the population aged 30-44, who are the driving force of housing demand. Looking first at Japan, in the 1980s bubble period the baby boomer generation entered the 35 to 40 age group, and the population aged 35 to 44 reached a historic peak. The movement among the age 35 to 44 population was especially notable. This population then decreased in tandem with the bubble's collapse, while in recent years, one can see that the younger generation has been entering the housing market in the 30 to 34 age range. In addition, a distinctive feature of Japan is that population influx from the outside through immigration is quite restricted, so the baby boomer peak has remained as is with the passage of time. In the U.S. on the other hand, the population aged 30 to 44 grew considerably through 2001, but rather than the population of a specific age group increasing as in Japan, the age 30 to 34 population group, age 35 to 40 population group, and age 40 to 44 population group all grew considerably. This shows that there was significant population influx from the outside, in contrast to Japan.

As for the dependency ratio, Nishimura (2011) shows that there exists a positive correlation between the inverse of the dependency ratio, which is defined as the ratio of the population aged 0-19 and 65+ to the population aged 20-64, and housing price fluctuations. Figure 3 shows the relationship between real estate prices and the dependency ratio for key regions in Japan and the U.S. In the figure, we also shows the old age dependency ratio, i.e. the ratio of population aged $65+$ to population aged 20-64, which is used in the empirical analysis by Takáts (2012). For these two ratios, we eliminate trend by applying the HodrickPrescott filter with the multiplier $\lambda$ set at 100. For Japan, one can see that Tokyo land prices peaked in 1988, while the old age dependency ratio consistently declined from 1980 to 1990, suggesting that the old age dependency ratio is inversely correlated with land prices. Similar tendency is observed between the dependency ratio and land prices. For Osaka, land prices, the old dependency ratio, and the dependency ratio moved in roughly the same manner as in Tokyo. However, in rural regions, such as Aomori and Kagawa, which did not experience any significant price hikes even during the 1980s bubble period, we do not see any clear negative relationship between land prices and demographic changes.

Turning to the U.S., we look at California, center of economic activity in the west, and New York, center of economic activity in the east. In both regions, significant increases in housing prices occurred in the latter half of the 1980s and the mid-2000s. Looking at the relationship with population indicators, the dependency ratio declined substantially in the late 1980s and the mid-2000s, suggesting a negative correlation between the two. Similarly, we can see a negative correlation between the age dependency ratio and housing prices. However, 
we do not see a clear negative correlation for Texas and West Virginia.

\section{Empirical Results}

\subsection{Tests on unit root}

We employ the two methods to test the stationarity of our panel data: (1) "common unit root test" in which the null hypothesis is that the time series in each region share a unit root; (2) "individual unit root test" in which the null is that the time series in each region has a different unit root.

Suppose that, for a panel series $y_{i t}$, a first order AR process is given by

$$
\begin{aligned}
& y_{i t}=\rho_{i} y_{i t-1}+\theta_{m i} d_{m t}+\epsilon_{i t} \\
& d_{1 t}=\{0\}, \quad d_{2 t}=\{1\}, \quad d_{3 t}=\{1, t\}
\end{aligned}
$$

for $i=1,2, \ldots, N, t=1,2, \ldots, T, m=1,2,3$. To test $\rho_{i}=1$, we run a regression of the form

$$
\Delta y_{i t}=\delta_{i} y_{i t-1}+\sum_{k=1}^{L_{i}} \gamma_{i k} \Delta y_{i t-k}+\theta_{m i} d_{m t}+\epsilon_{i t}
$$

The common unit root test proposed by Levin, Lin and Chu's (2002) is a unit root test that assumes regions have a common unit root, and the null and the alternative are given by

$$
H_{0}: \delta_{i}=\delta=0 ; \quad H_{1}: \delta_{i}=\delta<0
$$

where $\delta_{i}$ is defined by $\delta_{i} \equiv \rho_{i}-1=0$. The individual unit root test proposed by Im, Pesaran and Shin (2003) and Maddala and $\mathrm{Wu}$ (1999) is a unit root test that assumes the unit roots differ between regions. The null and the alternative hypotheses are given by

$$
H_{0}: \delta_{i}=0 \quad \text { for all } i
$$

and



We apply the above tests to real land price, population, the old age dependency ratio, new housing supply, income, and the interest rate. The results are given in Table 3 , showing that, for each of the six variables, the null is not rejected when the first difference is taken. ${ }^{5}$

\footnotetext{
${ }^{5}$ Note that the null is not rejected for some variables even without taking first difference. In what follows, however, we assume that all variables are $\mathrm{I}(1)$ and take first difference for all of them unless otherwise mentioned.
} 
Table 3: Unit Root Tests

\begin{tabular}{|c|c|c|c|c|c|c|c|c|}
\hline & \multicolumn{4}{|c|}{ Level } & \multicolumn{4}{|c|}{ First difference } \\
\hline & \multicolumn{2}{|c|}{$\begin{array}{l}\text { Common unit root } \\
\text { Levin-Lin-Chu }\end{array}$} & \multicolumn{2}{|c|}{$\begin{array}{c}\text { Individual unit root } \\
\text { ADF-Fisher }\end{array}$} & \multicolumn{2}{|c|}{$\begin{array}{l}\text { Common unit root } \\
\text { Levin-Lin-Chu }\end{array}$} & \multicolumn{2}{|c|}{$\begin{array}{c}\text { Individual unit root } \\
\text { ADF-Fisher }\end{array}$} \\
\hline \multicolumn{9}{|c|}{ Japan } \\
\hline Real land price & $\begin{array}{l}-5.7 \\
\end{array}$ & $(0.00)^{* * *}$ & 123 & $(0.03) * *$ & -12.9 & $(0.00) * * *$ & 333 & $(0.00) * * *$ \\
\hline Per capita GDP & -10.5 & $(0.00) * * *$ & 144 & $(0.00) * * *$ & -23.9 & $(0.00) * * *$ & 591 & $(0.00) * * *$ \\
\hline Dependency ratio & 0.6 & $(0.72)$ & 24 & $(1.00)$ & -3.1 & $(0.00) * * *$ & 94 & $(0.47)$ \\
\hline Population & 0.1 & $(0.53)$ & 99 & $(0.34)$ & -4.3 & $(0.00)^{* * *}$ & 89 & $(0.62)$ \\
\hline Real interest rate & -12.2 & $(0.00) * * *$ & 285 & $(0.00) * * *$ & -47.0 & $(0.00) * * *$ & 1347 & $(0.00) * * *$ \\
\hline New housing starts & 5.3 & $(1.00)$ & 50 & $(1.00)$ & -33.6 & $(0.00)^{* * *}$ & 1011 & $(0.00)^{* * *}$ \\
\hline \multicolumn{9}{|c|}{ U.S. } \\
\hline Real housing price & -6.9 & $(0.00)^{* * *}$ & 209 & $(0.00)^{* * *}$ & -9.1 & $(0.00) * * *$ & 379 & $(0.00)^{* * *}$ \\
\hline Per capita GDP & -3.4 & $(0.00) * * *$ & 50 & $(1.00)$ & -19.5 & $(0.00) * * *$ & 701 & $(0.00) * * *$ \\
\hline Dependency ratio & -4.3 & $(0.00) * * *$ & -6.3 & $(0.02) * *$ & -4.2 & $(0.00) * * *$ & -7 & $(0.00) * * *$ \\
\hline Population & -2.7 & $(0.00) * * *$ & 84 & $(0.89)$ & -18.6 & $(0.00) * * *$ & 547 & $(0.00) * * *$ \\
\hline Real interest rate & -2.8 & $(0.00) * * *$ & 230 & $(0.00) * * *$ & 0.0 & $(0.00)^{* * *}$ & 786 & $(0.00) * * *$ \\
\hline New housing starts & -3.6 & $(0.00) * * *$ & 225 & $(0.00) * * *$ & -18.2 & $(0.00) * * *$ & 536 & $(0.00) * * *$ \\
\hline
\end{tabular}

Note: Figures in the table represent test statistics with the associated p-values in parentheses. ${ }^{* * *}$, **, and ${ }^{*}$ indicate that the null hypothesis is rejected at the 1 percent, 5 percent, and 10 percent significance level. The lag of each ADF test is chosen based on the SIC criterion.

\subsection{Tests on cointegration}

We apply the following cointegration tests to our panel data. The first is the Kao test proposed by Kao (1999), which assumes that cointegration relationship in each region is identical. The second one is the Pedroni test proposed by Pedroni (1999), which assumes that cointegration relationship is heterogeneous across regions. Specifically, when we test cointegration between $y_{i t}$ and $x_{i t}$, we regress $y_{i t}$ on $x_{i t}$ to obtain an estimated error, which is denoted by $\hat{e}_{i t}$. Note that the Kao test assumes that the coefficient on $x_{i t}$ does not depend on $i$ while the Pedroni test allows the coefficient on $x_{i t}$ to be different across $i$. Then, we run a regression of the form

$$
\Delta \hat{e}_{i t}=\mu_{i} \hat{e}_{i t-1}+\sum_{k=1}^{L_{i}} \varphi_{i k} \Delta \hat{e}_{i t-k}+\epsilon_{i t}
$$

to see whether the estimate of $\mu_{i}$ is close to zero or not. The null and the alternative hypotheses in the Kao test are given by

$$
H_{0}: \mu_{i}=\mu=0 \quad H_{1}: \mu_{i}=\mu<0
$$

On the other hand, the null and the alternative hypotheses in the Pedroni test differ depending on whether homogeneity in terms of $\mu_{i}$ is assumed or not. If $\mu_{i}$ is assumed to be homogeneous 
Table 4: Cointegration Tests

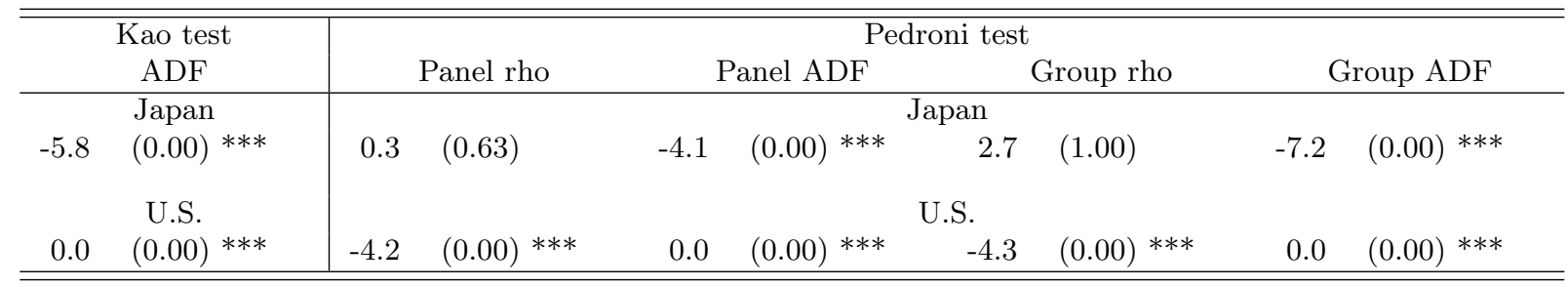

Note: Figures in the table represent test statistics with the associated p-values in parentheses. ${ }^{* * *},{ }^{* *}$, and ${ }^{*}$ indicate that the null hypothesis is rejected at the 1 percent, 5 percent, and 10 percent significance level. The lag of each ADF test is chosen based on the SIC criterion.

across $i$, which is referred to as the panel test, the null and the alternative are given by

$$
H_{0}: \mu_{i}=\mu=0 \quad H_{1}: \mu_{i}=\mu<0
$$

On the other hand, if one assumes that $\mu_{i}$ may not be identical across $i$, which is referred to as the group test, the null and the alternative hypotheses are given by

$$
H_{0}: \mu_{i}=\mu=0 \quad H_{1}: \mu_{i}<0 \text { for all } i
$$

We conduct cointegration tests for $\log$ land prices, $\ln P_{i t}$, the log of per capita GDP, $\ln G D P P C_{i t}$, the log of the old age dependency ratio, $\ln O L D D E P_{i t}$, and the log of population, $\ln T P O P_{i t}$. Specifically, we run a regression of the form

$$
\ln P_{i t}=\alpha_{i}+\beta_{1 i} \ln \operatorname{GDPPC}_{i t}+\beta_{2 i} \ln \operatorname{OLDDEP}_{i t}+\beta_{3 i} \ln \mathrm{TPOP}_{i t}+e_{i t}
$$

to obtain the estimate of $e_{i t}$ and the estimate of the corresponding $\mu_{i}$. The results are presented in Table 4, showing the presence of conintegration relationship among the four variables.

\subsection{Regression results}

Given that the four variables are cointegrated, we need to change our estimating equation, eq (1), into

$$
\Delta \ln P_{i t}=a_{i}+b_{1} \Delta \ln \mathrm{GDPPC}_{i t}+b_{2} \Delta \ln \mathrm{OLDDEP}_{i t}+b_{3} \Delta \ln \mathrm{TPOP}_{i t}+\mathrm{ECT}_{i t-1}+v_{i t} .
$$

The new term $\mathrm{ECT}_{i t-1}$ is the error correction term which is defined by

$$
\mathrm{ECT}_{i t} \equiv \ln P_{i t}-\left(\alpha_{i}+\beta_{1} \ln \mathrm{GDPPC}_{i t}+\beta_{2} \ln \mathrm{OLDDEP}_{i t}+\beta_{3} \ln \mathrm{TPOP}_{i t}\right)
$$


Table 5: Baseline Regressions

\begin{tabular}{|c|c|c|c|c|c|c|}
\hline & No. of OBS & Adj. R2 & GDP per capita & Old age dependency ratio & Total population & EC term \\
\hline \multicolumn{7}{|c|}{ Japan } \\
\hline & 1,645 & 0.629 & 0.2188 & -1.3167 & 0.9177 & -0.1033 \\
\hline s.e. & & & 0.067 & 0.202 & 0.341 & 0.011 \\
\hline$t$-stat & & & 3.25 & -6.50 & 2.69 & -9.66 \\
\hline \multicolumn{7}{|c|}{ U.S. } \\
\hline & 1,836 & 0.439 & 0.4515 & -0.9067 & 0.7514 & -0.1272 \\
\hline s.e. & & & 0.111 & 0.142 & 0.141 & 0.013 \\
\hline$t$-stat & & & 4.06 & -6.40 & 5.32 & -9.54 \\
\hline
\end{tabular}

Note: White's heteroskedasticity-consistent standard errors are reported.

Note that we add time dummies to eq. (10) in our baseline regression, which capture unobserved price fluctuations across regions, although we employ a specification without time dummies as robustness check. ${ }^{6}$

The regression results are presented in Table 5. We see that each of the estimated coefficients is statistically significant and meet the corresponding sign condition. However, the estimated coefficients differ to some extent between the two countries. The coefficient on per capita GDP is greater in the U.S. than in Japan; it is 0.2188 in Japan while it is 0.4515 in the U.S. However, the two coefficients associated with demographic changes are larger in Japan. Specifically, the coefficient on Japan's old age dependency ratio is -1.3167 while the corresponding coefficient in the U.S. is -0.9067. The coefficient on total population in Japan is 0.9177 and the corresponding estimate in the U.S. is 0.7514 .

When comparing with the results of Takáts (2012) estimated using panel data from 22 countries, the coefficient on the per capita GDP is 0.8842 , the coefficient on the old age dependency ratio is -0.6818 and the coefficient on the total population is 1.0547. Since the estimation period differs with Takáts (2012) from 1970 and this paper from 1975, a simple comparison cannot be made, but our estimate for the coefficient on per capita GDP in Japan is much smaller than the Takáts estimate. As for the coefficients regarding demographic changes, the coefficient on the old age dependency ratio is much larger than the corresponding Takáts estimates, while the coefficient on total population is almost identical.

In Figure 4, we decompose changes in the real land price over the last 30 years (i.e. 19762010) into the contribution of per capital GDP growth and the contribution of demographic

\footnotetext{
${ }^{6}$ For the specification test, we run (a) a F-test for OLS and fixed effects model, (b) Lagrange multiplier test based on OLS residuals, and (c) Hausman test for fixed and random effects model. These tests show that a random effects model is appropriate for this equation. We, however, estimate a fixed effects model to put an emphasis on the comparison with the results of Takáts (2012).
} 
changes, which is defined as the sum of the contribution of OLDDEP and that of TPOP. Figure $4 \mathrm{a}$ shows the result for the entire sample period, while Figures $4 \mathrm{~b}$ and $4 \mathrm{c}$ show the results for subsample periods (i.e. 1976-1990 for Figure 4b and 1991-2010 for Figure 4c). Real land prices rose by 0.8 percent per year for the entire sample period. Decomposing this into the economic and demographic factors, the contribution of the economic factors (i.e. the contribution of per capita GDP growth) is +0.2 percent per year while the contribution of demographic changes is -3.7 percent per year. In subsamples, the land price inflation rate was 7.3 percent per year for 1976-1990, while it was -3.4 percent per year for 1990-2010. For the period of 1976-1990, the contribution of economic growth is +0.6 percent per year while the contribution of demographic changes is -2.9 percent per year. For the period of 19902010 , the contribution of economic growth is -0.1 percent per year while the contribution of demographic changes is -4.2 percent per year. Note that the price decline in the latter period is mainly due to demographic changes, although low economic growth during this period also contributed to the price decline.

Figure 4 also shows that the regions with positive demographic impacts in 1976-2010 were only areas surrounding Tokyo, such as Ibaraki, Kanagawa, Saitama and Chiba, and areas such as Nara and Shiga, which are adjacent to Osaka, center of the second largest economic zone, and Okinawa. As seen in Figure 4b, the contribution of demographic changes in those areas was much larger in 1976-1990. Note that the contribution of demographic changes was consistently negative in Tokyo, suggesting that population outflowed to suburban areas due to high housing prices in Tokyo resulting from the housing bubble.

To check the robustness of the regression results, we estimate different versions of eq (10). First, we change the specifications of the estimating equation by (1) dropping the time dummies; (2) adding regional dummies; (3) dropping the error correction term. Note that eq (10) coincides with the original specification adopted by Takáts (2012) if one keeps the time dummies but drops the error correction term. The results are presented in Table 6, showing that the coefficients of our interest, i.e., the coefficients on the old age dependency ratio and on the total population, are of the same sign as in the baseline specification, and significantly different from zero. However, the absolute size of the estimated coefficients tends to be larger than in the baseline specification, suggesting that the demographic impact may be slightly underestimated in the baseline specification.

Second, we add new variables to eq (10) such as the interest rate and new housing supply. ${ }^{7}$

\footnotetext{
${ }^{7}$ For the interest rate, we use the average contractual interest rate on bank loans for Japan, and the contract rate on 30-year, fixed-rate conventional home mortgage commitments for the U.S. Note that the interest rate data was not available by region, so that we use national figures. The nominal interest rates are converted into real terms by subtracting consumer price inflation, which is available by region. As for new housing supply,
} 
Table 6: Robustness Check

\begin{tabular}{|c|c|c|c|c|c|c|}
\hline \multicolumn{7}{|c|}{ Japan } \\
\hline Specification & $\begin{array}{l}\text { Per capita } \\
\text { GDP }\end{array}$ & $\begin{array}{l}\text { Old age } \\
\text { dep ratio }\end{array}$ & Population & $\begin{array}{l}\text { Interest } \\
\text { rate }\end{array}$ & $\begin{array}{l}\text { Housing } \\
\text { supply }\end{array}$ & EC term \\
\hline Baseline specification (BS) & $0.2188^{* * *}$ & $-1.3167^{* * *}$ & $0.9177^{* * *}$ & & & $-0.1033^{* * *}$ \\
\hline No time dummies & $0.4401^{* * *}$ & $-1.9702^{* * *}$ & $2.5376^{* * *}$ & & & $-0.0993^{* * *}$ \\
\hline Regional dummies & $0.2302^{* * *}$ & $-1.7280^{* * *}$ & $2.0220^{* * *}$ & & & $-0.1056^{* * *}$ \\
\hline Regional dummies \& No time dummies & $0.3891^{* * *}$ & $-2.2071^{* * *}$ & $4.0806^{* * *}$ & & & $-0.0951^{* * *}$ \\
\hline No EC term & $0.1468^{* *}$ & $-1.0790^{* * *}$ & $0.8333^{* *}$ & & & \\
\hline $\mathrm{BS}+$ Interest rate & $0.1433^{* *}$ & $-1.4071^{* * *}$ & $1.0508^{* * *}$ & $0.0079^{* * *}$ & & $-0.1115^{* * *}$ \\
\hline BS+Housing supply & $0.2297^{* * *}$ & $-1.2701^{* * *}$ & $1.1372^{* * *}$ & & $-0.0901^{* * *}$ & $-0.0916^{* * *}$ \\
\hline BS+Interest rate+Housing supply & $0.1664^{* *}$ & $-1.3675^{* * *}$ & $1.2517^{* * *}$ & $0.0073^{* * *}$ & $-0.0862 * * *$ & $-0.1069^{* * *}$ \\
\hline $\mathrm{BS}+$ Interest rate+HS with a lag & 0.0890 & $-1.3569 * * *$ & $1.1941 * * *$ & $0.0082^{* * *}$ & $-0.0794 * * *$ & $-0.1080 * * *$ \\
\hline \multicolumn{7}{|c|}{ U.S. } \\
\hline Specification & $\begin{array}{l}\text { Per capita } \\
\text { GDP }\end{array}$ & $\begin{array}{l}\text { Old age } \\
\text { dep ratio }\end{array}$ & Population & $\begin{array}{l}\text { Interest } \\
\text { rate }\end{array}$ & $\begin{array}{l}\text { Housing } \\
\text { supply }\end{array}$ & EC term \\
\hline Baseline specification (BS) & $0.4515^{* * *}$ & $-0.9067^{* * *}$ & $0.7514^{* * *}$ & & & $-0.1272^{* * *}$ \\
\hline No time dummies & $0.5874^{* * *}$ & $-1.1576^{* * *}$ & $0.6163^{* * *}$ & & & $-0.1143^{* * *}$ \\
\hline Regional dummies & $0.4525^{* * *}$ & $-0.5363^{* * *}$ & $1.8079^{* * *}$ & & & $-0.1199^{* * *}$ \\
\hline Regional dummies \& No time dummies & $0.5847^{* * *}$ & $-1.2666^{* * *}$ & $0.8503^{* * *}$ & & & $-0.1116^{* * *}$ \\
\hline No EC term & $0.4714^{* * *}$ & $-0.7821^{* * *}$ & $0.8222^{* * *}$ & & & \\
\hline $\mathrm{BS}+$ Interest rate & $0.4415^{* * *}$ & $-0.9375^{* * *}$ & $0.7385^{* * *}$ & -0.0020 & & $-0.1328^{* * *}$ \\
\hline BS+Housing supply & $0.3819^{* * *}$ & $-0.7824^{* * *}$ & $0.6308^{* * *}$ & & $0.0430^{* * *}$ & $-0.1292^{* * *}$ \\
\hline BS+Interest rate+Housing supply & $0.3725^{* * *}$ & $-0.8128^{* * *}$ & $0.6139^{* * *}$ & -0.0018 & $0.0422^{* * *}$ & $-0.1356^{* * *}$ \\
\hline $\mathrm{BS}+$ Interest rate+HS with a lag & $0.4555^{* * *}$ & $-0.6489^{* * *}$ & $0.4272^{* * *}$ & 0.0027 & $0.0432^{* * *}$ & $-0.1358^{* * *}$ \\
\hline
\end{tabular}

Note: ${ }^{* * *},{ }^{* *}$, and ${ }^{*}$ indicate that the null hypothesis that the estimated coefficient is zero is rejected at the 1 percent, 5 percent, and 10 percent significance level.

For the specification with the interest rate, the coefficient on the interest rate is negative for the U.S., which is consistent with the theoretical prediction. However, the coefficient is not statistically significant. For Japan, the coefficient on the interest rate is positive, inconsistent with the theoretical prediction, although it is not significantly different from zero. Turning to new housing supply, the coefficient associated with it is negative and statistically significant, implying that an increase in housing supply exerts downward pressure on land prices. In the U.S., on the other hand, the coefficient on housing supply is positive and significantly different from zero, which is consistent with the implication of stock flow models, in which housing price hikes leads to an increase in new housing supply.

Finally, we replace GDPPC $_{i t}$ with GDPPC $_{i t-1}$ in order to eliminate the potential endogeneity problem. The coefficient on per capita GDP is now smaller than before, but it is still positive and significantly different from zero.

we use housing start data for both Japan and the U.S. 


\section{Demographic Impact over the Next 30 Years}

In this section, we forecast real land prices in Japan using the regression coefficients obtained in the previous section, as well as the projection on demographic changes released by the IPSS, which were based on natural increases/decreases calculated from the survival probability and the number of births by cohort and social increases/decreases due to movement between regions. Population projections used in the paper are the medium variant projection, which is based on the assumption of medium fertility, unless otherwise mentioned.

Figure 5 shows the contributions of demographic changes over that past 35 years (1976 to 2010) as well as over the next 30 years (2011 to 2040). All figures represent percentage contributions per year. As far as the national average is concerned, the contribution of demographic changes over the past 35 years was -3.7 percent per year, ${ }^{8}$ while it will be -2.4 percent per year over the next 30 years. The contribution of demographic changes is negative in all regions, but it is more pronounced in rural areas, suggesting that, in these rural areas, the decline in real estate prices will be accelerated by substantial population outflow to the urban areas.

Figure 6a shows the cumulative contribution of demographic changes on real land prices: it shows the cumulative contributions in 2011-2020, 2011-2030, 2011-2040. This suggests that in many prefectures, real land prices in 2040 will drop by about 50 percent from their current levels, but there will even be drops of 70 to 80 percent in the rural areas such as Hokkaido, Aomori, and Ibaraki, so one can see that the effects of demographic changes on land prices will be extreme.

Figure 6a uses future population estimates that take inter-prefectural population migration into account, but Figure 6b looks at the extent to which the impact of demographics on land prices changes if one assumes that there will no such migration. In this figure, we plot the difference between land prices if there is population movement and land prices if there is no population movement. As seen in the figure, the difference exceeds zero for the seven prefectures including Tokyo, Aichi, and Osaka, while it is below zero for the other prefectures, suggesting that inter-prefecture immigration from rural to urban areas will contribute to an increase in land price inequality across regions.

\footnotetext{
${ }^{8}$ The contribution of demographic changes in 1976-1990 was -2.9 percent per year, while it was -4.2 percent per year in 1991-2010.
} 
Table 7: Contributions of Demographic Changes With and Without Inter-prefectural Migration

\begin{tabular}{|c|c|c|c|c|c|c|}
\hline \multirow[b]{2}{*}{ Prefecture } & \multicolumn{3}{|c|}{ With migration } & \multicolumn{3}{|c|}{ Without migration } \\
\hline & 2020 & 2030 & 2040 & 2020 & 2030 & 2040 \\
\hline Hokkaido & $-41.5 \%$ & $-54.0 \%$ & $-68.2 \%$ & $-39.8 \%$ & $-52.0 \%$ & $-64.9 \%$ \\
\hline Aomori & $-41.9 \%$ & $-57.7 \%$ & $-70.8 \%$ & $-38.3 \%$ & $-51.3 \%$ & $-61.8 \%$ \\
\hline Iwate & $-36.2 \%$ & $-50.5 \%$ & $-63.3 \%$ & $-33.1 \%$ & $-44.9 \%$ & $-54.7 \%$ \\
\hline Miyagi & $-34.9 \%$ & $-47.5 \%$ & $-61.9 \%$ & $-33.9 \%$ & $-47.0 \%$ & $-60.2 \%$ \\
\hline Akita & $-41.2 \%$ & $-57.0 \%$ & $-68.7 \%$ & $-37.3 \%$ & $-50.2 \%$ & $-58.5 \%$ \\
\hline Yamagata & $-36.8 \%$ & $-50.8 \%$ & $-62.3 \%$ & $-34.0 \%$ & $-45.3 \%$ & $-53.3 \%$ \\
\hline Fukushima & $-38.6 \%$ & $-53.2 \%$ & $-65.6 \%$ & $-32.9 \%$ & $-45.2 \%$ & $-54.4 \%$ \\
\hline Ibaraki & $-38.4 \%$ & $-48.7 \%$ & $-63.5 \%$ & $-38.4 \%$ & $-48.9 \%$ & $-62.0 \%$ \\
\hline Tochigi & $-38.1 \%$ & $-49.4 \%$ & $-64.2 \%$ & $-38.0 \%$ & $-49.5 \%$ & $-62.7 \%$ \\
\hline Gunma & $-34.6 \%$ & $-43.9 \%$ & $-60.6 \%$ & $-34.9 \%$ & $-44.4 \%$ & $-59.0 \%$ \\
\hline Saitama & $-34.4 \%$ & $-43.1 \%$ & $-62.4 \%$ & $-37.0 \%$ & $-48.6 \%$ & $-66.4 \%$ \\
\hline Chiba & $-36.2 \%$ & $-45.0 \%$ & $-63.1 \%$ & $-36.7 \%$ & $-47.8 \%$ & $-65.1 \%$ \\
\hline Tokyo & $-23.0 \%$ & $-34.1 \%$ & $-58.5 \%$ & $-31.5 \%$ & $-48.6 \%$ & $-71.0 \%$ \\
\hline Kanagawa & $-29.1 \%$ & $-39.6 \%$ & $-61.3 \%$ & $-32.5 \%$ & $-47.0 \%$ & $-67.6 \%$ \\
\hline Niigata & $-33.1 \%$ & $-44.9 \%$ & $-59.5 \%$ & $-32.0 \%$ & $-43.0 \%$ & $-54.8 \%$ \\
\hline Toyama & $-33.6 \%$ & $-41.2 \%$ & $-58.8 \%$ & $-34.4 \%$ & $-42.0 \%$ & $-56.8 \%$ \\
\hline Ishikawa & $-34.8 \%$ & $-42.5 \%$ & $-58.6 \%$ & $-35.3 \%$ & $-44.0 \%$ & $-57.9 \%$ \\
\hline Fukui & $-32.1 \%$ & $-44.0 \%$ & $-58.8 \%$ & $-29.9 \%$ & $-40.3 \%$ & $-51.7 \%$ \\
\hline Yamanashi & $-31.4 \%$ & $-46.4 \%$ & $-63.4 \%$ & $-29.3 \%$ & $-42.6 \%$ & $-57.2 \%$ \\
\hline Nagano & $-29.7 \%$ & $-40.5 \%$ & $-58.3 \%$ & $-29.0 \%$ & $-38.2 \%$ & $-52.6 \%$ \\
\hline Gifu & $-30.9 \%$ & $-40.5 \%$ & $-57.3 \%$ & $-30.8 \%$ & $-40.0 \%$ & $-54.2 \%$ \\
\hline Shizuoka & $-32.9 \%$ & $-43.5 \%$ & $-60.3 \%$ & $-32.6 \%$ & $-43.5 \%$ & $-58.0 \%$ \\
\hline Aichi & $-26.3 \%$ & $-33.5 \%$ & $-54.1 \%$ & $-29.2 \%$ & $-40.1 \%$ & $-59.4 \%$ \\
\hline Mie & $-28.3 \%$ & $-38.3 \%$ & $-56.0 \%$ & $-29.4 \%$ & $-40.0 \%$ & $-55.3 \%$ \\
\hline Shiga & $-29.2 \%$ & $-37.1 \%$ & $-54.2 \%$ & $-30.9 \%$ & $-41.3 \%$ & $-56.6 \%$ \\
\hline Kyoto & $-33.2 \%$ & $-40.4 \%$ & $-58.4 \%$ & $-31.8 \%$ & $-40.4 \%$ & $-57.0 \%$ \\
\hline Osaka & $-30.0 \%$ & $-37.8 \%$ & $-59.6 \%$ & $-31.4 \%$ & $-40.9 \%$ & $-60.8 \%$ \\
\hline Hyogo & $-30.9 \%$ & $-40.1 \%$ & $-58.9 \%$ & $-31.9 \%$ & $-42.4 \%$ & $-59.2 \%$ \\
\hline Nara & $-36.2 \%$ & $-46.8 \%$ & $-63.0 \%$ & $-34.5 \%$ & $-44.7 \%$ & $-58.9 \%$ \\
\hline Wakayama & $-33.4 \%$ & $-45.7 \%$ & $-61.7 \%$ & $-31.9 \%$ & $-42.4 \%$ & $-55.2 \%$ \\
\hline Tottori & $-36.0 \%$ & $-47.8 \%$ & $-60.1 \%$ & $-32.6 \%$ & $-42.1 \%$ & $-50.8 \%$ \\
\hline Shimane & $-31.7 \%$ & $-41.9 \%$ & $-54.6 \%$ & $-28.7 \%$ & $-36.3 \%$ & $-44.0 \%$ \\
\hline Okayama & $-29.0 \%$ & $-34.8 \%$ & $-50.3 \%$ & $-29.8 \%$ & $-36.6 \%$ & $-50.0 \%$ \\
\hline Hiroshima & $-33.7 \%$ & $-41.0 \%$ & $-57.4 \%$ & $-32.8 \%$ & $-41.3 \%$ & $-55.8 \%$ \\
\hline Yamaguchi & $-36.0 \%$ & $-42.7 \%$ & $-56.5 \%$ & $-34.6 \%$ & $-40.3 \%$ & $-50.7 \%$ \\
\hline Tokushima & $-40.9 \%$ & $-51.9 \%$ & $-64.9 \%$ & $-38.5 \%$ & $-47.8 \%$ & $-58.1 \%$ \\
\hline Kagawa & $-35.4 \%$ & $-43.7 \%$ & $-58.8 \%$ & $-34.5 \%$ & $-42.1 \%$ & $-54.3 \%$ \\
\hline Ehime & $-34.5 \%$ & $-45.0 \%$ & $-59.1 \%$ & $-32.7 \%$ & $-42.2 \%$ & $-53.5 \%$ \\
\hline Kochi & $-39.1 \%$ & $-49.7 \%$ & $-63.0 \%$ & $-36.1 \%$ & $-44.6 \%$ & $-54.6 \%$ \\
\hline Fukuoka & $-36.0 \%$ & $-44.5 \%$ & $-59.0 \%$ & $-34.6 \%$ & $-44.4 \%$ & $-57.3 \%$ \\
\hline Saga & $-34.4 \%$ & $-45.5 \%$ & $-56.3 \%$ & $-32.4 \%$ & $-41.7 \%$ & $-48.8 \%$ \\
\hline Nagasaki & $-37.7 \%$ & $-51.4 \%$ & $-63.4 \%$ & $-33.7 \%$ & $-44.9 \%$ & $-52.9 \%$ \\
\hline Kumamoto & $-32.8 \%$ & $-44.0 \%$ & $-54.8 \%$ & $-30.8 \%$ & $-41.4 \%$ & $-48.9 \%$ \\
\hline Oita & $-33.1 \%$ & $-41.0 \%$ & $-52.6 \%$ & $-32.8 \%$ & $-41.1 \%$ & $-50.1 \%$ \\
\hline Miyazaki & $-36.7 \%$ & $-47.5 \%$ & $-57.2 \%$ & $-34.2 \%$ & $-43.7 \%$ & $-49.6 \%$ \\
\hline Kagoshima & $-36.6 \%$ & $-49.4 \%$ & $-59.3 \%$ & $-33.0 \%$ & $-43.4 \%$ & $-48.9 \%$ \\
\hline Okinawa & $-30.0 \%$ & $-43.4 \%$ & $-57.8 \%$ & $-30.4 \%$ & $-44.1 \%$ & $-55.5 \%$ \\
\hline
\end{tabular}


Table 8: Contribution of Demographic Changes Estimated Based on IPSS and UN Population Projections

\begin{tabular}{lrrr}
\hline \hline \multicolumn{4}{c}{ Estimates based on population projection by IPSS } \\
\hline & $\begin{array}{r}\text { Low variant } \\
\text { projection }\end{array}$ & $\begin{array}{r}\text { Medium variant } \\
\text { projection }\end{array}$ & $\begin{array}{r}\text { High variant } \\
\text { projection }\end{array}$ \\
\hline TPOP $_{2010}$ & 102,350 & 128,057 & \\
TPOP $_{2040}$ & & 107,276 & 112,506 \\
OLDDEP $_{2010}$ & 0.712 & 0.390 & \\
OLDDEP $_{2040}$ & -0.025 & 0.717 & 0.722 \\
Demographic impact on land prices & -0.024 & -0.023 \\
\hline \hline
\end{tabular}

\begin{tabular}{lrrr}
\hline & $\begin{array}{r}\text { Low variant } \\
\text { projection }\end{array}$ & $\begin{array}{r}\text { Medium variant } \\
\text { projection }\end{array}$ & $\begin{array}{r}\text { High variant } \\
\text { projection }\end{array}$ \\
\hline $\mathrm{TPOP}_{2010}$ & & 128,057 & \\
$\mathrm{TPOP}_{2040}$ & 106,182 & 114,517 & 122,988 \\
$\mathrm{OLDDEP}_{2010}$ & & 0.390 & \\
OLDDEP$_{2040}$ & 0.734 & 0.704 & 0.676 \\
Demographic impact on land prices & -0.025 & -0.022 & -0.019 \\
\hline \hline
\end{tabular}

Note: IPSS projections are from "Population Projections for Japan (January 2012)" released by the National Institute of Population and Social Security Research (IPSS), which is available at http://www.ipss.go.jp/site-ad/index_english/esuikei/gh2401e. asp. UN projections are from "World Population Prospects: The 2012 Revision," which is available at http://esa.un.org/unpd/wpp/index.htm. The figures for TPOP are in thousand.

Finally, we check the robustness of the result by conducting the same exercise using different population projections. We use the low and high variant projections, both of which are released by the IPSS, instead of the medium variant projection. The low variant projection is based on the assumption of low fertility but high mortality rates, while the high variant is based on the assumption of high fertility but low mortality rates. We also use the UN population projections, which are taken from "World Population Prospects: The 2012 Revision." The result is presented in Table 8. For the estimates based on the IPSS projections, the total population in 2040 varies between 102 million and 112 million, while the old age dependency ratio in 2040 varies between 0.712 and 0.722 . However, the resulting estimate on the demographic impact on land prices does not change that much from the one obtained in the case of the medium variant projection. ${ }^{9}$ We also confirm that the result does not change

\footnotetext{
${ }^{9}$ Note that the old age dependency ratio in 2040 will be as high as 0.752 with the combination of low fertility
} 
that much even if we use the UN projections instead of the IPSS projections.

\section{Conclusion}

In this paper, we have empirically investigated how real estate prices are affected by aging in Japan and the United States. We find that, both in Japan and the U.S., real estate prices in a region are inversely correlated with the old age dependency ratio in that region, and positively correlated with the total number of population in that region.

The demographic factor had a greater impact on real estate prices in Japan than in the U.S. Based on the regression result for Japan and the population forecast made by a government agency, we find that it will be -2.4 percent per year in 2012-2040 while it was -3.7 percent per year in 1976-2010, suggesting that aging will continue to have downward pressure on land prices over the next 30 years, although the demographic impact will be slightly smaller than it was in 1976-2010 as the old age dependency ratio will not increase as much as it did before.

\section{References}

[1] Baltagi, Badi (2005), Econometric Analysis of Panel Data, Third edition, Wiley.com.

[2] Engelhardt, G. V. and J. M. Poterba (1991), "House Prices and Demographic Change: Canadian Evidence," Regional Science and Urban Economics, Vol. 21, 539-546.

[3] Engle, Robert F., and C. W. J. Granger (1987), "Co-integration and Error Correction: Representation, Estimation, and Testing," Econometrica, Vol. 55 (2), 251-276.

[4] Hamilton, B. W. (1991), "The baby boom, the baby bust, and the housing market: A second look," Regional Science and Urban Economics, Vol. 21, 547-552.

[5] Hendershott, P. H. (1991), "Are real house prices likely to decline by 47 percent," Regional Science and Urban Economics, Vol. 21, 553-563.

[6] Im, K.S., M.H. Pesaran, and Y. Shin (2003), "Testing for Unit Roots in Heterogeneous Panels," Journal of Econometrics, Vol. 115, 53-74.

[7] Kao, C. (1999), "Spurious Regression and Residual-Based Tests for Cointegration in Panel Data," Journal of Econometrics, Vol. 90, 1-44.

and low mortality rates. In this case, the estimate on the demographic impact on land prices is -0.026 , which is again not that much different from the estimate obtained in the case of the medium variant projection. 
[8] Kawamura, K. and C. Shimizu (2013), "Dynamics of Housing Prices," Reitaku International Journal of Economic Studies, forthcoming.

[9] Levin, A., C. F. Lin, and C. S. J. Chu (2002), "Unit Root Tests in Panel Data: Asymptotic and Finite-Sample Properties," Journal of Econometrics, Vol.108, 1-24.

[10] Maddala, G. S. and S. Wu (1999), "A Comparative Study of Unit Root Tests with Panel Data and New Simple Test," Oxford Bulletin of Economics and Statistics, Vol. $61,631-652$.

[11] Mankiw, N. G., and D. N. Weil (1989), "The baby boom, the baby bust, and the housing market," Regional Science and Urban Economics, Vol. 19, 235-258.

[12] Martin, Robert F. (2005), "The Baby Boom: Predictability in Housing Prices and Interest Rates," International Finance Discussion Papers 2005-847, Federal Reserve Board, November 2005.

[13] Nagahata, T. Y. Saita, T. Sekine, T. Tachibana (2004), "Equilibrium Land Prices of Japanese Prefectures: A Panel Cointegration Analysis," Bank of Japan Working Paper Series 04-E-9.

[14] Nakamura, K. and Y. Saita (2007), "Land Prices and Fundamentals," Bank of Japan Working Paper Series 07-E-8.

[15] Nishimura, K. G. (2011), "Population Ageing, Macroeconomic Crisis and Policy Challenges," Presented at the Panel on "The General Theory and the Policy Reponses to Macroeconomic Crisis" at the 75th Anniversary Conference of Keynes' General Theory, University of Cambridge, June 19-21, 2011.

[16] Nishimura, K. G. and E. Takáts (2012), "Ageing, property prices and money demand," BIS Working Papers, No 385.

[17] Ohtake, F. and Shintani, M. (1996), "The effect of demographics on the Japanese housing market," Regional Science and Urban Economics, Vol. 26, 189-201.

[18] Pedroni, P. (1999), "Critical Values for Cointegration Tests in Heterogeneous Panels with Multiple Regressors," Oxford Bulletin of Economics and Statistics, Vol. 61, 653-670.

[19] Shimizu, C. and K. G. Nishimura (2006), "Biases in Appraisal Land Price Information: The Case of Japan," Journal of Property Investment and Finance, Vol. 26, No. 2, 150175. 
[20] Shimizu, C and T. Watanabe (2010), "Housing Bubble in Japan and the United States," Public Policy Review Vol. 6, No. 3, 431-472.

[21] Shimizu, C., W. E. Diewert, K. G. Nishimura and T. Watanabe (2012), "The Estimation of Owner Occupied Housing Indexes using the RPPI: The Case of Tokyo," RIPESS Working Paper, No. 50.

[22] Takáts, E (2012), "Aging and house prices," Journal of Housing Economics, Vol. 21, No. 2, June, 131-41. 




Figure 1: Japanese and U.S. Home Ownership Rates by Age Group





Figure 2: Japanese and U.S. Population by Age Group 
Japan:

(Index: 1970=100)



(Index: 1970=100)

Aomori



_ Real land price in log (left scale)

- - - - Old age dependency ratio(right scale)

$\longrightarrow$ Dependency ratio(right scale)

US:

(Index: 1970=100)

California



Real housing price in log (left scale)

- - - O Old age dependency ratio(right scale)

$\longrightarrow$ Dependency ratio(right scale)

(Index: 1970=100)

Texas



$\begin{array}{llllllll}1975 & 1980 & 1985 & 1990 & 1995 & 2000 & 2005 & 2010\end{array}$

Real housing price in log (left scale)
$\ldots$ - Old age dependency ratio(right scale)
$\ldots$ Dependency ratio(right scale)
(Index: $1970=100) \quad$ Osaka



(Index: 1970=100) Kagawa



— Real land price in log (left scale)

- - - Old age dependency ratio(right scale)

$\longrightarrow$ Dependency ratio(right scale)
.000

0.040

$-0.060$

0.080 




Figure 4a: Decomposition of Land Price Changes over 1976-2010



Figure 4b: Decomposition of Land Price Changes over 1976-1990 




Figure 4c: Decomposition of Land Price Changes over 1991-2010



Figure 5: Historic and Forecasted Demographic Impacts on Land Prices 




Figure 6a: Contributions of Demographic Changes in 2011-2040



Figure 6b: Effects of Inter-Prefectural Migration on Demographic Impacts in 2011-2040 




Figure A1: Land Prices Forecasted



Figure A2: Land Prices Forecasted with the Assumption of No Inter-Prefectural Migration 